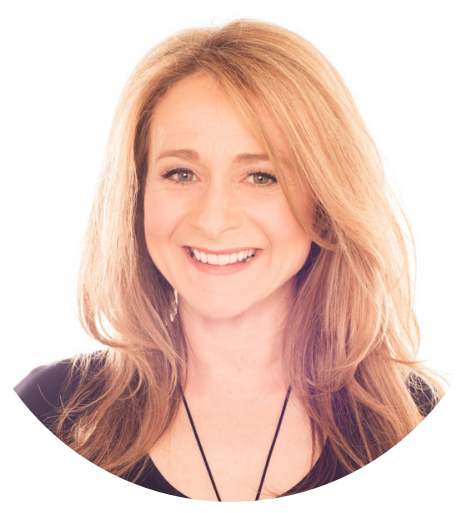

\section{BACK TO THE FUTURE}

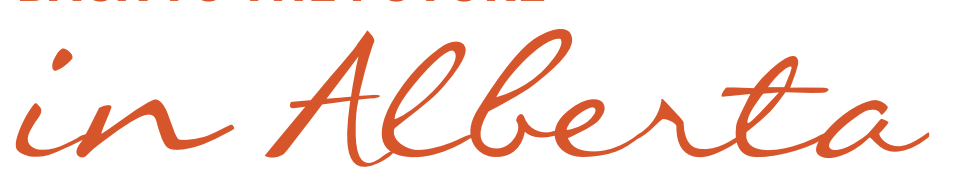

Monica Kidd MD

- Cite as: CMAJ 2017 May 15;189:E708. doi: $10.1503 / \mathrm{cmaj} .170474$

\begin{abstract}
Coda: the concluding passage to a piece or movement, typically forming an addition to the basic structure. It's a fitting title for our new back-page column, which will highlight voices from Canadian physicians on myriad topics, clinical to metaphysical. Our opening columns will be written by Dr. Monica Kidd, a poet, seabird biologist, radio journalist, mother and, now, family doctor in Calgary. If you're curious about her unusual career, you can read a profile about her in the Jan. 9, 2017, issue. We hope you enjoy this new feature and, as always, we welcome your feedback.
\end{abstract}

W

hen I was in training, I vowed that if I ever wrote a memoir I won't - it would be called Just a Family Doctor. As in the question everyone seemed to ask back then: "Are you going to be a specialist, or just a family doctor?" The year I started medical school, less than a quarter of graduating Canadian medical students ranked family medicine as their first choice in the Canadian Resident Matching Service application. But perhaps because finding work as a medical or surgical specialist is not as easy as it once was, and because of the efforts family doctors have made to sell their field to medical students, last year $36 \%$ of medical grads ranked family medicine first. The title of my would-be memoir began to seem a little silly.

But lately I've begun to wonder if I shouldn't dust it off.

In 2015, Alberta's NDP government announced it would rein in health spending. According to the 2017 budget, Alberta spends $\$ 21.4$ billion on health annually, more than $40 \%$ of its total budget. Physician billing accounts for $\$ 5.2$ billion, and $\$ 2.2$ billion goes to drugs; Alberta Health's 2015/16 annual report indicates that facility- and care-based services (scroll down, Rusty, scroll waaay down), come in at a combined $\$ 7.4$ billion. And so on. The government asked the Alberta Medical Association to help it figure out how it could spend less in a way that would cause the least weeping and gnashing of teeth. Which is when things started to get ugly.

Everyone knows that family doctors are the lowest-paid physicians, and radiologists and ophthalmologists are among the highest paid. The Canadian Medical Association's publication New In Practice 2017 states that average annual fee-for-service billings for family docs range from a low of $\$ 215000$ in Nova Scotia to a high of \$333000 in Alberta; the most highly paid doctors reported in the publication are ophthalmologists, who bill an average low of $\$ 590000$ in Nova Scotia and a high of $\$ 1.1$ million in Alberta. (Incomes of radiologists are not reported.) Do I think the gap should be narrower? Sure I do. Just as I think the gap should be narrower between CEOs and average workers. Because inequality reduces social cohesion and leads to any number of poor health outcomes - just do a PubMed search for some sobering reading on that.

But I don't think we all need to be paid the same. One idea on the table for how the government might spend less on physician billing, but do so in a fair way, is the Adjusted Net Daily Income (ANDI). It's a massive actuarial undertaking that collects data on billings from various specialties, then applies corrections for overhead costs, opportunity costs ("the money you didn't make" during your lengthy training) and hours worked in a day. (I would hope an ANDI process would also somehow, impossibly, take into consideration overall service provided; maybe a GGI, a Gross Goodness Index.)

Let's take my husband and me as an example. He's an orthopedic surgeon. His residency was five years long plus two years of fellowship, whereas my post-grad training was two years. When he does a weekend of call, the kids often go for several days without seeing him. He helps people walk again, and the stakes for his patients are life and limb. I truly don't begrudge that he makes three times as much as I do.

Dr. Padraic Carr, president of the Alberta Medical Association, has said this process of trimming health expenditures should not become a fight between family docs and specialists. But sadly, some of us are dropping the gloves. In a private email forwarded to me, an anonymous specialist (highly paid, he or she gloats) called Alberta Health and the Alberta Medical Association "a communist regime" and family doctors people who "did not make the cut."

Looks like it's still 2004 in some people's minds.

I suppose it goes back to the tragedy of the commons that when a resource is limited, it is human nature to hang on more tightly to what we think we own or are owed. But really, can't we all give our heads a shake and remember that for all of our stress and hard work, doctors have it pretty good? It's unbecoming for any of us to forget that. 